NBER WORKING PAPER SERIES

\title{
VALUATION AND OPTIMAL EXERCISE OF THE WILD CARD OPTION IN \\ THE TREASURY BOND FUTURES MARKET
}

Alex Kane

Alan J. Marcus

Working Paper No. 1614

NATIONAL BUREAU OF ECONOMIC RESEARCH 1050 Massachusetts Avenue Cambridge, MA 02138

May 1985

The research reported here is part of the NBER's research program in Financial Markets and Monetary Economics. Any opinions expressed are those of the authors and not those of the National Bureau of Economic Research. 


\author{
Valuation and Optimal Exercise of \\ the Wild Card option in \\ the Treasury Bond Futures Market
}

\title{
$\underline{\text { ABSTRACT }}$
}

The Chicago Board of Trade Treasury Bond Futures Contract allows the short position several delivery options as to when and with which bond the contract will be settled. The timing option allows the short position to choose any business day in the delivery month to make delivery. In addition, the contract settlement price is locked in at 2:00 p.m. When the futures market closes, despite the facts that the short position need not declare an intent to settle the contract until 8:00 p.m. and that trading in Treasury bonds can occur all day in dealer markets. If bond prices change significantly betiveen 2:00 and 8:00 p.m., the short has the option of settling the contract at a favorable 2:00 p.m. price. This phenomenon, which recurs on every trading day of the delivery month, creates a sequence of 6-hour put options for the short position which has been dubbed the "wild card option." This paper presents a valuation model for the wild card option and computes estimates of the value of that option, as well as rules for its optimal exercise.

Alex Kane

School of Management Boston University 704 Commonwealth Avenue Boston, MA 02215
Alan J. Marcus School of Management Boston University 704 Commonwea 1 th Avenue Boston, MA 02215 


\section{Introduction}

The Treasury bond futures contract on the Chicago Board of Trade gives several delivery options to the short position. The quality option, which allows the short to deliver any of several eligible delivery bonds, has already been studied fairly extensively. Because many bonds are eligible to be delivered against the futures contract, and the conversion factors used to adjust for the bond actually delivered do not perfectly reflect relative price differences, the short-side trader will choose to deliver the "cheapest" eligible bond. Kilcollin (1982) presents a discussion and analysis of conversion factors and their effects on the optimal delivery bond. Gay and Manaster (1984a) present a theoretical valuation model for the quality option when two classes of commodities with uncertain end-of-period spot prices may be delivered. Garbade and Silber (1983) provide a similar analysis and estimate parameters of the valuation formula for a variety of agricultural commodity futures. Kane and Marcus (1984) have used Monte Carlo simulations to value the quality option in the Treasury bond futures market.

In contrast, the various timing options embedded in the delivery process have received comparatively little attention. One of the most important of these is the so-called wild card option. The wild card option arises because the futures market closes each trading day at ? p.m. (Central Standard Time), which locks in the futures settlement price for the rest of the day, while the short trader has until $8 \mathrm{p} . \mathrm{m}$. of each trading day in the delivery month to declare an intent to deliver on the contract. Because government bonds trade in a dealer market that is effectively open until the $8 \mathrm{p} . \mathrm{m}$. delivery-notice deadline, a 5-hour "put option" is created at 2:00 p.m., which allows the short trader to deliver the bond at that day's settlement price. 
The short-side trader "exercises" his option by choosing at 8:00 p.m. to deliver at that afternoon's 2:00 p.m. settlement price. Otherwise, the contract is continued into the next day. That day, the contract is marked to market and by 8:00 p.m. the short position once again must decide whether to deliver. This process continues until delivery, which is required to be made by the end of the delivery month.

One recent paper that deals explicitly with the wild card option is by Gay and Manaster (1984b). That paper considers a simple delivery rule for the futures contract, and simulates the use of the rule for the 1977-1983 period to derive an empirical assessment of the value of the wild card option. No theoretical valuation formula for the option is offered, however. Moreover, we will argue below that the Gay-Manaster trading rule is not value-maximizing for the short position.

The derivation of both the optimal exercise strategy and the valuation formula for the wild card option are complicated by the presumption that, in equilibrium, the futures price must be bid down by the value of the option. Because the payoff to the option depends upon the futures price, which in turn impounds the option value, the determination of the valuation and exercise rules requires the solution of a fixed-point problem. This simultaneity is often overlooked; for example, Gay and Manaster's (1984b, p. 9) exercise rule implies that, in the absence of transaction costs, delivery should be made whenever spot bond prices decrease after 2 p.m. ${ }^{1}$ In fact, we demonstrate below that bond prices must decline by more than a critical value before delivery is optimal. The excess profit offered by delivering at 8 p.m. over that of marking to market on the next trading day must compensate the short position for the fact that the wild card option expires upon exercise. This 
feature makes the delivery decision an optimal stopping problem: once the short trader chooses to deliver, potentially more profitable future exercise of the option is no longer possible. Hence, the delivery profit inust be large enough to compensate for the loss of the right to carry the wild card option into the next trading day.

This paper presents a valuation model for the wild card option. We show that the option is in some ways similar to an American option with the unusual feature that, at the start of each trading day, the exercise price is readjusted to put the option out of the money. Section II contains a discussion of the features of the delivery process in the T-bond market that create the wild card option, and presents a valuation formula for the option. This valuation rule gives the amount by which the equilibrium T-bond futures prices should be bid down in equilibrium to compensate the long position for the delivery option conveyed to the short position. Section III is devoted to numerical exercises that demonstrate the quantitative significance of the option. We find that the value of the option at the start of the delivery month can be 20 cents (off the current futures price of 65 dollars). This value is smaller than, but of the same order of magnitude, as the value of the quality option (Kane and Marcus, 1984). Finally, Section IV contains a summary and discussion of the implications of our results.

\section{The Delivery Process and the Valuation of the Wild Card Option}

The basic trading unit in the CBT T-bond futures market is a $\$ 100,000$ face value U.S. Treasury bond. Any such T-bond with a maturity of at Teast 15 years which is not callable for at least 15 years from the first day of the delivery month may be delivered to settle the contract. In order to adjust 
for differences in the values of deliverable grade bonds, the CBT establishes conversion factors (CF) to determine actual payments at the delivery of the contract. The long side of each contract pays the short side an amount equal to the futures contract settlement price times the conversion factor. The CF is chosen to adjust for the relative values of the admissible delivery grade bonds. The CF equals the fraction of par value for which the delivery bond would sell if it were priced to offer an 8 percent yield to maturity. Bonds with coupon rates above 8 percent will have a CF greater than one, and conversely for bonds below 8 percent.

Al though the futures price is frozen for the day as of 2:00 p.m., the short side trader has unti1 8:00 p.m. to announce his intent to deliver. If he delivers, the conversion factor of the delivery bond is calculated and the long-side trader is invoiced for an amount equal to $q F_{2 p m}(t)$, where $q$ is the conversion factor and $F_{2 p m}(t)$ is the closing futures (settiement) price at date t. Letting $B_{8 \mathrm{pm}}(t)$ denote the market value of the delivered bond, the short position's profit from delivery is ${ }^{2}$

$$
\mathrm{qF}_{2 p m}(t)-B_{8 p m}(t)
$$

If the short chooses not to deliver, the contract is continued to the next day. The expected (as of $3: 00 \mathrm{p.m}$. On day $t$ ) profit or loss to the short position from the next day's marking to market is

$$
F_{2 p m}(t)-E_{8 p m, t}\left[F_{2 p m}(t+1)\right]
$$

where the second term in (2) denotes the expected value of the next day's closing futures price based on the information available as of 3:00 p.m. 
If there are no transactions costs involved in establishing a position in the futures market, then the short will choose to deliver if expression (1) is greater than (2). ${ }^{3}$ with no transaction costs, any position in the futures market may be re-established after the profits from either strategy (1) or (2) are realized. To operationalize the delivery rule, an expression for $E_{8 p m, t}\left[F_{2 p m}(t+1)\right]$ is required.

To derive such an expression, note that if the futures market were open continuously, then at all times during the delivery month the futures price and spot price of the currently-optimal delivery bond would have to satisfy the no-arbitrage condition

$$
\pi(t)=q F(t)-B(t)=0
$$

or

$$
F(t)=B(t) / q
$$

where $\pi(t)$ is the profit to the short side and the optimal delivery bond is the one which minimizes the price to conversion factor ratio, $B(t) / q$.

In reality, the short position may choose to deliver at 8:00 p.m. at the closing (2:00 p.m.) futures price, or if it is more profitable, may continue the contract to the next day, and mark to market. To reflect this option, the equilibrium futures price must be bid down by the option's value $V(t)$, so that the observed futures prices, $F(t)$ must be

$$
F(t)=3(t) / q-V(t) .
$$


Notice that if a contract were settled while the futures market were open, the profit from settiement would be

$$
\begin{aligned}
\pi(t) & =q F(t)-B(t) \\
& =-q V(t) .
\end{aligned}
$$

The short trader would suffer a loss equal to the wasted wild card option scaled by the conversion factor. In fact, one would expect that the contract would never be settled prior to $3: 00 \mathrm{p} . \mathrm{m}$., since the option should be worth more al ive than dead. ${ }^{4}$ Thus, the settle versus mark to market decision wil1 be made each day at 8:00 p.m., and the sequence of delivery decisions can be treated as occurring once each day during the delivery month.

Using (3), we immediately deduce that

$$
E_{8 p m, t}\left[F_{2 p m}(t+1)\right]=E_{8 p m, t}\left[B_{2 p m}(t+1) / q-V_{2 p m}(t+1)\right]
$$

With no trend growth in the bond price lor alternatively, noting that trend growth over one day is of second-order importance compared with daily price fluctuations), the expectation of $B_{2 p m}(t+1)$ is simply the current price, $B_{8 p m}(t) .5$ Moreover, $V_{2 p m}(t+1)$ is nonstochastic: as of 2:00 p.m. on date $t+1$, before any bond price movements occur while the futures market is closed and the settlement price is locked in for the day, the option value is a function only of time to maturity and the parameters of bond price dynamics. Since the bond price and futures price have not yet become misaligned, the option value is independent of the actual level of the bond price. In fact, its value for any day in the future at times during which the futures market is open is nonstochastic. 5 Hence, (4) becomes 


$$
E_{8 p m, t}\left[F_{2 p m}(t+1)\right]=B_{8 p m}(t) / q-v_{2 p m}(t+1)
$$

and the expected profit from marking to market is

$$
F_{2 p m}(t)-\left[B_{8 p m}(t) / q-V_{2 p m}(t+1)\right]
$$

or, using (3) for $F_{2 p m}(t)$,

$$
\begin{gathered}
{\left[B_{2 p m}(t) / q-V_{2 p m}(t)\right]-\left[B_{8 p m}(t) / q-V_{2 p m}(t+1)\right]} \\
=-\Delta B / q-\left[V_{2 p m}(t)-V_{2 p m}(t+1)\right]
\end{gathered}
$$

where $\Delta B=B_{3 p m}(t)-B_{2 p m}(t)$.

Finally, comparing the profits from marking to market [equation (6)] with those from delivery [equation (1)], the condition at 8:00 p.m. for continuing the contract rather than delivering is

$$
-\Delta B / q-\left[V_{2 p m}(t)-V_{2 p m}(t+1)\right]>\Delta B-q V_{2 p m}(t)
$$

and the incremental profit of marking to market over that of delivering is

$$
x_{t}=\Delta B(1-1 / q)+(q-1) V_{2 p m}(t)+v_{2 p m}(t+1)
$$

Equations (7) and (8) highlight the difference between our formulation and that of Gay and Manaster (1984b). They derive the optimal delivery strategy without accounting for the impact of the wild card option on the futures 
price. (See their equations (2) and (3).) Consequently, the last two terms in (8) do not appear in their delivery rule, and they conclude that in the absence of delivery costs, and with a conversion factor greater than one, the short should deliver whenever bond prices decline between 2:00 p.m. and 8:00 p.m. ${ }^{7}$ In contrast, equation ( $(3)$ demonstrates that the delivery decision cannot be predicted by simple rules of thumb. On one hand, marking to market continues the contract and keeps the wild card option alive into the next day. This is reflected in the term $\mathrm{qV}_{2 \mathrm{pm}}(\mathrm{t})$ in equation (8); this consideration discourages delivery. On the other hand, (8) shows that one must aiso consider the change in the value of the option as time passes. Since the value of the wild card option must decrease as the delivery month nears its end, $V(t+1)$ will be less than $V(t)$, so that $F(t+1)-F(t)$ will be larger than would be suggested by movements in the spot bond market alone. Consequent1y, marking to market produces lower profits for the short position than would be indicated by changes in the spot price alone; this pattern encourages delivery.

Notice also the crucial role played by the conversion factor in the valuation of the wild card option. If the conversion factor equals 1.0 , then the only value for the option that is consistent with $(7)$ or $(8)$ is $V(t)=0$ for all t. For $q=1$, delivering and marking to market produce identical profits. As a diverges from 1, however, the value of the option to choose between delivering and marking to market can grow rapidly.

The role of the conversion factor in determining settlement behavior may best be understood by considering the $C F$ as a scale factor. The daily profit to the short position from a mark to market strategy equals $(-\Delta B / q-\Delta V)$ while the settlement strategy gives a profit of $-\Delta B-q V$. When bond prices fall, 
the short position profits. Note however, that the profit accruing from the bond price decline is divided by $q$ in the mark to market strategy. Hence, when $q$ exceeds 1.0 , settlement will tend to dominate marking to market for bond price decreases, because marking to market scales down profits by $1 / q$. Conversely, for increases in bond prices, the short position suffers a loss that $c$ an be scaled down by the factor $1 / q$ by marking to market. Hence, ignoring the option value (and transaction costs), the optimal settlement rule for $q>1$ would be to settle whenever bond prices fall after 2:00 p.m. and mark to market when prices rise. The delivery rule should be reversed for $q<$ 1 , since then the factor $1 / q$ exceeds 1.0 , and scales up profits or losses. This rule was simulated by Gay and Manester (1984b) using past contracts.

When the value of the option is also considered, the settle versus mark to market decision is more complicated, since settlement forfeits the right to carry the option into the next trading day. Hence settlement requires that bond prices fall by more than a finite critical value (for $q>1$ ) before settlement is optimal. However, the role of the conversion factor as a scaling factor remains. In fact, one might view the wild card option as the right to scale up profits by a factor of $q$ when bond prices fall (for $q>1$ ) or to scale down losses by that factor when prices rise (for $q<1$ ) on the day that the option is exercised. ${ }^{3}$ Hence, it is clear that the optimal strategy is to wait for an afternoon with large price swings before setting the contract.

Implementation of equation (8) as a means of determining when to deliver requires that the value of the wild card option as a function of time left in the delivery month be known. This is the standard optimal stopping problem (DeGroot, 1970). Fortunately one can solve (8) recursively to determine that 
valuation formula. Consider first the value of the option on the last day that the contract is traded, which we will denote by $T$. At this date, the short position's wild card option is valueless. The last change in the futures price has been recorded, and there is no longer an option to mark to market rather than to deliver. ${ }^{9}$ Hence, $V_{2 p m}(T)=0$.

At 2:00 p.m. on date $T-1$, the short has one more six-hour period in which the choice between delivering or marking to market may be made. The expected profit is thus

$$
E_{2 p m, T-1}[\max \text { (settlement profit, mark-to-market profit)] }
$$

The equilibrium condition in the futures market (assuming no risk premium to either side of the contract) is that expression (9) equal zero. Rewriting (9), we obtain

$$
E_{2 p m, T-1}\left(\text { settlement profit) }+E_{2 p m, T-1}\left[\max \left(X_{T-1}, 0\right)\right]=0\right.
$$

where $x_{t}$ was defined in equation (8). But the expected settlement profit is simply $E_{2 p m, T-1}\left[\left(-B_{8 p m}(T-1)+q F_{2 p m}(T-1)\right]\right.$. Since the expected end-of-day bond price equals the current price (see footnote 5), and with $F_{2 p m}(T-1)=B_{2 p m}(T-1) / q-V_{2 p m}(T-1)$ by equation (3), the expected 8:00 p.m. settlement profit is

$$
-B_{2 p m}(T-1) \div q\left[B_{2 p m}(T-1) / q-V_{2 p m}(T-1)\right]=-q V_{2 p m}(T-1)
$$

and equation (10) becomes 


$$
-q V_{2 p m}(T-1)+E_{2 p m, T-1}\left[\max \left(X_{T-1}, 0\right)\right]=0
$$

or

$$
V_{2 p m}(T-1)=(1 / q) E_{2 p m, T-1}\left[\max \left(X_{T-1}, 0\right)\right]
$$

The realization of $X_{T-1}$ depends on $B_{8 p m}(T-1)$ which is a random variable as of 2:00 p.m. on day $T-1$.

The solution to

$$
V(t)=E_{2 p m, t}\left[\max \left(X_{t}, 0\right)\right] / q
$$

requires the determination of a fixed point since $V(t)$ is itself part of $x_{t}$ and thus appears on the right-hand side of (13). However, given the probability distribution for $\mathrm{B}_{8 \mathrm{pm}}(\mathrm{t})$ conditional on information available at 2:00 p.m. On date $t$, the expectation of $x_{t}$ for a given $V(t)$ is easily calculated, and determination of the fixed point is a straightforward numerical exercise.

Once $V(T-1)$ is determined, equation (13) can be solved for $V(T-2)$, and so on back to the first day of the delivery month. The end result is a schedule, $V(t)$, for each date $t$ during the delivery month. This schedule can then be used by the short position in conjunction with equation (7) to determine at 8:00 p.m. of each delivery day whether delivering or marking to market is the appropriate strategy. The exercise strategy is straightforward: mark to market if $x_{t}$ is greater than zero; otherwise settle the contract.

For example, using the assumption that next-day bond prices are distributed lognormally with mean drift equal to zero, the expectation in (13) equals 


$$
\begin{array}{cl}
(1 / q)\left[\lambda B N\left(d_{1}\right)-E N\left(d_{2}\right)\right] & \text { for } q>1 \\
(1 / q)\left[\lambda B\left[1-N\left(d_{1}\right)\right]-E\left[1-N\left(d_{2}\right)\right]\right] & \text { for } q<1
\end{array}
$$

where

$$
\begin{aligned}
& \lambda=1-1 / q \\
& B=\text { current bond price } \\
& E=\lambda B+(1-q) V(t)+V(t+1) \\
& d_{1}=(1 / \sigma)\left[\ln (\lambda B / E)+\sigma^{2} / 2\right] \\
& d_{2}=d_{1}-\sigma \\
& \sigma^{2}=\text { the variance of the six-hour bond return } \\
& N(.)=\text { the cumulative standard normal distribution function. }
\end{aligned}
$$

Because the one-step-ahead value of the option is already established (as we work backwards from time T), an iterative technique can be used to solve (14) for $V(t)$. Notice that $V(t)$ appears on the RHS of $(14)$ in $E$. Hence, at each step of the solution, the fixed point for $V(t)$ in (14) must be calculated.

\section{Numerical Results}

In order to quantify the value of the wild card option, we present solutions to equation (14) for several configurations of the delivery bond's conversion factor and standard deviation of bond returns. The value $V(t)$ that results is the amount by which the futures price should be bid down in equilibrium because of the option.

We considered conversion factors of $0.75,1.25,1.5$, and 1.75. Conversion factors of bonds currently eligible for delivery range from approximately 1.0 
to 1.75 . The standard deviation of annual bond returns was set to either .05 , .10 , or .20. These values correspond to the range of values calculated by Bodie, Kane, and McDonald (1934) for bond return variability during different subperiods in the 1970 s and 1980s. The six hour standard deviations of the bond rate of return were calculated from the annual standard deviations on the basis of 52 trading weeks per year with five trading days per week. We also assumed that the spot bond market supports active trading for 12 hours a day. The range that we consider for the annual standard deviation, 5-20 percent, should account for the fact that the number of trading days per week and hours per day need not be exactly as assumed.

Figure 1 is a graph of the value of the wild card option as a function of trading days remaining in the delivery month. Because trading in the contract is suspended seven business days prior to the end of the month, there are typically no more than 16 days on which the wild card play can be made. Three curves appear in Figure 1, corresponding to the three posited values for standard deviation in conjunction with a conversion factor of 1.5. As expected, the value of the wild card option increases with the delivery bond's standard deviation. The value of the option rises quickly as days renaining in the delivery month increase from zero, but the rate of increase falls steadily with time to maturity. At the start of the delivery month, with 16 days remaining until the contract stops trading, the value for the option reaches $\$ .083, \$ .165$, and $\$ .329$ per contract on $\$ 100$ of $T$-bond par value, for the three standard deviations respectively. These values are smaller than, but of the same order of magnitude as the value of the quality option calculated in Kane and llarcus (1984). The quality option (i.e., the value of the short position's right to choose the optimal delivery bond) for contracts 
three months prior to the delivery month was calculated to be in the range of $\$ 1.39$ to $\$ 4.60$. As the delivery month approaches and the delivery bond becomes more easily predicted, the quality option diminishes in importance, and the wild card option becomes more important for the short position.

Figure 2 is similar in design to Figure 1, but examines the impact of the conversion factor on the option value. The calculations here use the mid-point annual standard deviation value of 10 percent. In this case the values of the wild card option at the start of the delivery month equal 8.277, $\$ .114, \$ .165$, and $\$ .189$ for the conversion factors $.75,1.25,1.5$, and 1.75 respectively. The value of the option is obviously quite sensitive to the difference between the conversion factor and 1.0. Since the conversion factors themselves increase with the difference between the coupon rate of the delivery bond and the eight percent coupon rate of the benchmark bond on which the contract is nominally written, the value of the wild card option will vary with the general level of market yields. Thus, if market yields were permanently to fall from current levels, so that all delivery bonds would have coupon rates closer to eight percent, the wild card option would be devalued.

Figures 3 and 4 demonstrate the amount by which the delivery bond's price must rise or fall on any afternoon in order to induce the short position to initiate delivery. Equation ( 8 ) shows that when $x_{t}$ is negative, settlement of the contract will be optimal. For conversion factors greater than one, this will require a bond price decrease. We have calculated the necessary decrease for honds intitially selling at par value (\$100). Figures 3 and 4 show that with few days left in the delivery month, even slight declines in bond price will set of delivery. Because there is little time left in which to obtain a "favorable draw" from the distribution of bond-price changes, the 
value of the wild card option is low, and even small decreases dictate contract settlement. However, as time remaining in the delivery month increases, the condition for settlement becomes more stringent. The analysis is symmetric for conversion factors less than one. Figures 3 and 4 also illustrate the bond price increase required to initiate delivery when $q<1$.

Because of the sensitivity of bond prices to weekly money-supply announcements, one might argue that the week ly variance rate of bond returns ought to be "concentrated" on the announcement day. We examine the impact of this potential nonstationarity in Figures 5 and 6 , in which the annual standard deviation of bond-price changes is kept equal to the midrange value in Figures 1 and 3 (i.e., 10 percent), but in which the standard deviation of every fifth day's return is made to be $(1+k)$ times as large as the previous four days' standard deviation. Increases in $k$ thus correspond to greater concentration of price movements on the money-supply announcement day. Values of $k$ equal to 0.5 and 1.5 are considered, and the conversion factor 1.5 is used. The values in Figure 5 and 6 thus may be compared to the midrange curves in Figures 1 and 2 , since all use identical conversion factors and annual standard deviations. The option values in Figure 5 are all slightly greater than the corresponding values in Figures 1 and 2, reflecting the fact that valuation function is convex in the bond-return standard deviation.

The outstanding feature of Figure 5 is the dramatic dependence of the option value on potential price movement during the announcement day. For the extreme case, $k=1.5$, the option value is almost flat for days in-between announcements. Virtually the entire value of the option accrues from the bond-price varjability associated with the three announcement days of each delivery month. The decrease in bond price necessary to set off a settlement, 
which is depicted in Figure 6 , is correspondingly spiked at announcement days. Figure 6 demonstrates that the critical price decrease required to induce contract settlement increases dramatically for each announcement day left in the delivery month, while it is almost unaffected by the remaining number of non-announcement days.

\section{Conclusion}

We have developed a valuation framework for the wild card option implicit in the Treasury=bond futures contract. Market equilibrium requires that the futures price be bid down by the value of this option. For the current set of delivery bonds, and with an annual standard deviation of 10 percent, our results indicate that the value of the option at the start of the delivery month is consistent with the futures price being bid down by approximately one-fifth of a point (from a current base of roughly $\$ 68$ ). As the month draws to its end, however, the option value approaches zero.

Our valuation framework also gives rise to a value-maximizing contractsettlement rule. We presented the critical bond-price decreases necessary to induce contract settlement as a function of days left in the delivery month and the bond's variance rate and coversion factor.

A natural question arises as to whether actual settlement behavior of traders closely mimics that dictated by our model. Gay and Manester (1984b) conclude that traders act suboptimally and that futures prices are consistent with that suboptimal settlement behavior. If so, delivery behavior based on the rules derived herein should provide the short position with superior profits. We currently are simulating the use of these rules using past contracts to examine their efficacy in increasing the short positions's potential profit. 


\section{FOOTNOTES}

1. This rule is reversed when the delivery bond's conversion factor falls below 1.0. However, the conversion factor exceeds one for virtually a 11 eligible (non-flower) bonds.

2. The invoice price also includes the accrued interest on the delivered bond. For expositional simplicity, we will omit this term in the following analysis. Since the actual profit at delivery is $-B+(q F+A)=$ $-(B-A)+q F$, where $A$ is the accrued interest, one can think of the short position as delivering the bond stripped of its accrued interest in return for $q F$. Hence $B$ in our notation may be considered the net-of-accrued-interest value of the bond. This is the price at which the bond is quoted in the security market.

3. This formulation ignores the uncertainty involved in the mark-to-market strategy. If that risk is not diversifiable, a discount factor could be applied to $(2)$.

4. It is conceivable that for some specifications of interest rate dynamics, settlement prior to 8:00 p.m. could be optimal. For example, with a strongly mean-reverting interest rate process, a large interest rate increase and associated bond-price decrease early in the afternoon would tend to be followed by bond-price recovery. Settlement before the anticipated recovery could then be value maximizing. Such a possibility is rule out by the log-normal bond-price dynamics that we posit. If we were to use a stochastic process for which settlement prior to 8:00 p.m. were an important possibility, then equation (13) below would underestimate the value of the wild card option.

5. Letting $A$ denote accrued interest on the delivery bond, the short's profit upon delivery actually equals $[-(B-A)+q F]$, and (3) becomes 


$$
F(t)=[3(t)-A(t)] / q-V(t)
$$

Hence, one actually requires in $(4)$ that $3_{2 \mathrm{pm}}(t+1)$ include the trend growth in the value of the bond less its accruing interest, or put differently, the trend growth in the quoted price of the bond. This will be quite close to zero for bonds selling near par. It is simple to add a growth factor to $\mathrm{B}_{8 \mathrm{pm}}(t)$ to account for the expected one-day growth in the net-of-accrued-interest bond price. Our valuation estimates results were virtually unaffected by such an addition, and we therefore ignore it to avoid cluttering the notation. We also assume here that the optimal delivery bond for the next day is known as of 8:00 p.m.

6. As noted, because the futures price continually adjusts along with the bond price to new information during the trading day, it will never be optimal to deliver prior to $2: 00 \mathrm{p.m}$, and indeed delivery before 8:00 p.m. would be highly unlikely. Only when bond prices decline after 2:00 p.m. is it profitable to settle. After 2:00 p.m., the option value moves in response to bond price fluctuations. Until then the value is fixed. If, at 3:00 p.m., settlement is not chosen, the option takes on its next-day's value which is, again, fixed until 2:00 p.m. This feature distinguishes the wild sard option from more conventional American options. When the futures market reopens every morning, the futures price immediately adjusts to reflect the information that arrived since 2:00 p.m. on the previous afternoon. Thus, the option goes immediately out of the money at the start of each day.

7. When the conversion factor is less than 1.0 , increases in the price of the delivery bond will cause the short position to settle the contract. The term multiplying $\Delta B$ in equation (3) changes sign when q passes though 1.0. This issue is discussed further below. 
8. This insight suggests an easy way to eliminate the wild card option. Rather than use the CF to scale up the invoice price to reflect the "quality" of the delivery bond, which results in profits $q F-B$, the CF could be used to scale down the number of bonds required to satisfy the contract. This procedure would result in settlement profits to the short position of F-B/q. Marking to market would thus result in identical profits as settlement, and this complicating effect on contract strategy would be eliminated.

9. This date is actually 7 business days prior to the end of the delivery month. At that time, the futures market is closed and the settlement price no longer changes. While the short has the right to decide when during this last week to deliver, he is obligated to deliver by the end of the week at the given settlement price, and with no special information regarding the one-week movement in the bond price, the value of this "waiting option" should be negligible. 


\section{REFERENCES}

Bodie, Z.; Kane, A.; McDonald, R.1., 1984, "Why Haven't Nominal Rates Declined," Financial Analysts Journal, 40, 16-27.

DeGroot, M.H., 1970, Optimal Statistical Decisions, New York: McGraw-Hi11 Book Company.

Garbade, K. and W.L. Silber, 1983, "Futures Contracts on Commodities with Multiple Varieties: An Analysis of Premiums and Discounts, "Journal of Business, 56, 249-271.

Gay, G.D. and S. Manaster, 1984a, "The Quality Option Implicit in Futures Contracts," Journal of Financial Economics, 13, 353-370.

$$
\text { 1984b, "Implicit Delivery Options and Optimal }
$$

Delivery Strategies for Financial Futures Constraints," Working Paper

CSFM-95, Center for the Study of Futures Markets, Columbia University.

Kane, A. and A.J. Marcus, 1984, "An Assessment of Delivery Risk in the Treasury Bond Futures Market," Working Paper CSFM-96, Center for the Study of Futures Markets, Columbia University.

Kilcollin, T.E., 1982, "Difference Systems in Financial Futures Markets," Journal of Finance, 37, 1183-1197.

Kolb, R.W., G.D. Gay, and J. Jordan, 1982, "Are There Arbitrage Opportunities in the T-bond Futures Market," Journal of Futures Markets, 2, 217-229.

Phillips, S.M. and C.W. Smith, 1980, "Trading Costs for Listed Options: The Implications for Market Efficiency," Journal of Financial Economics, 8, 179-201.

Resnick, B. and E. Hennigar, 1983, "The Relation Between Futures Prices and Cash Prices for U.S. Treasury Bonds," Review of Research in Futures Markets, 2, 282-299. 


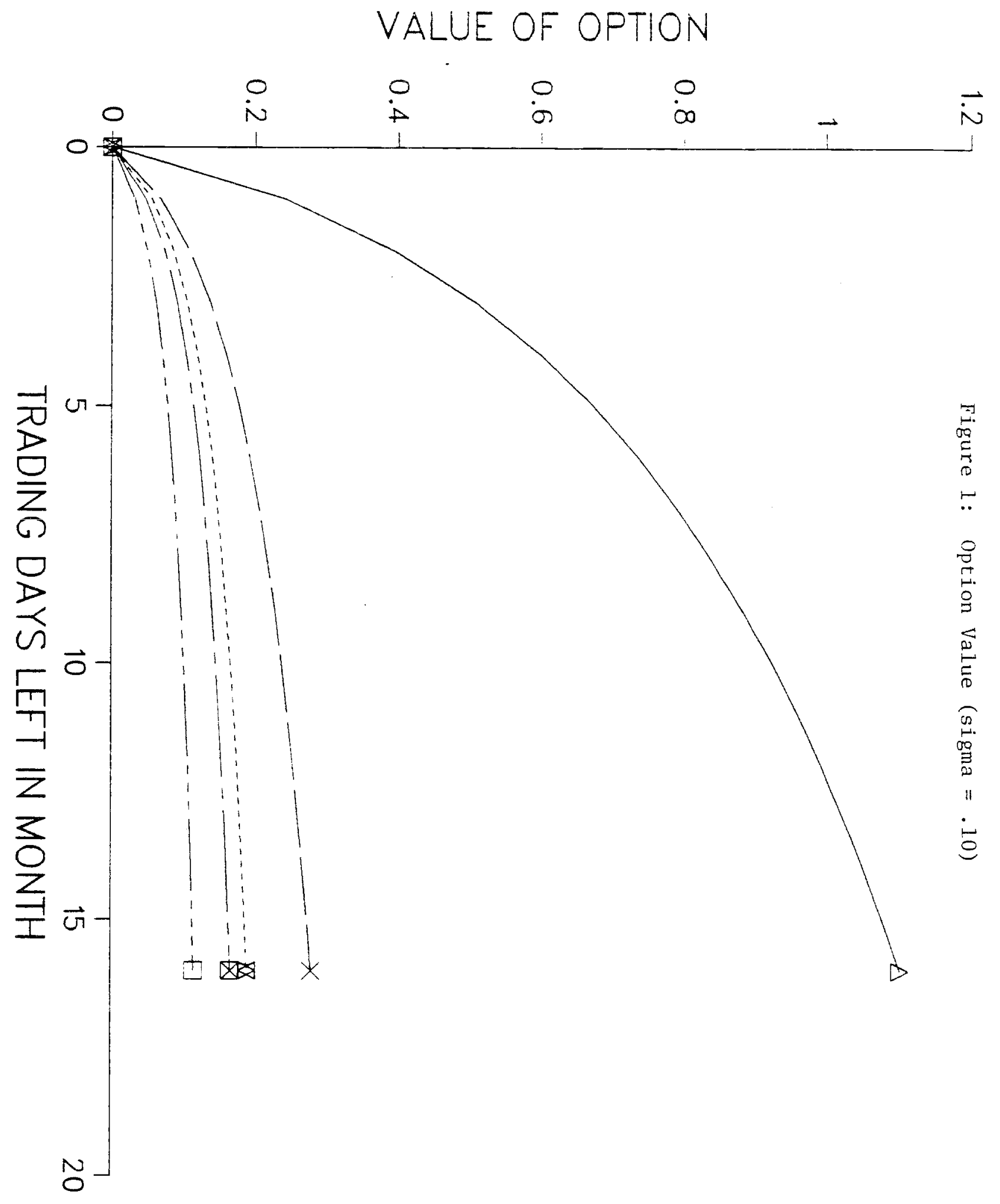

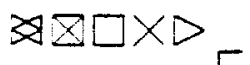

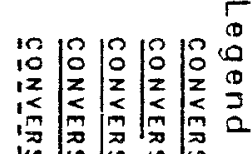

垈

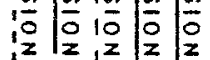

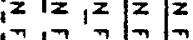

is

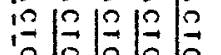

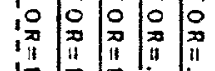

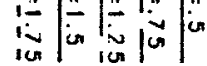




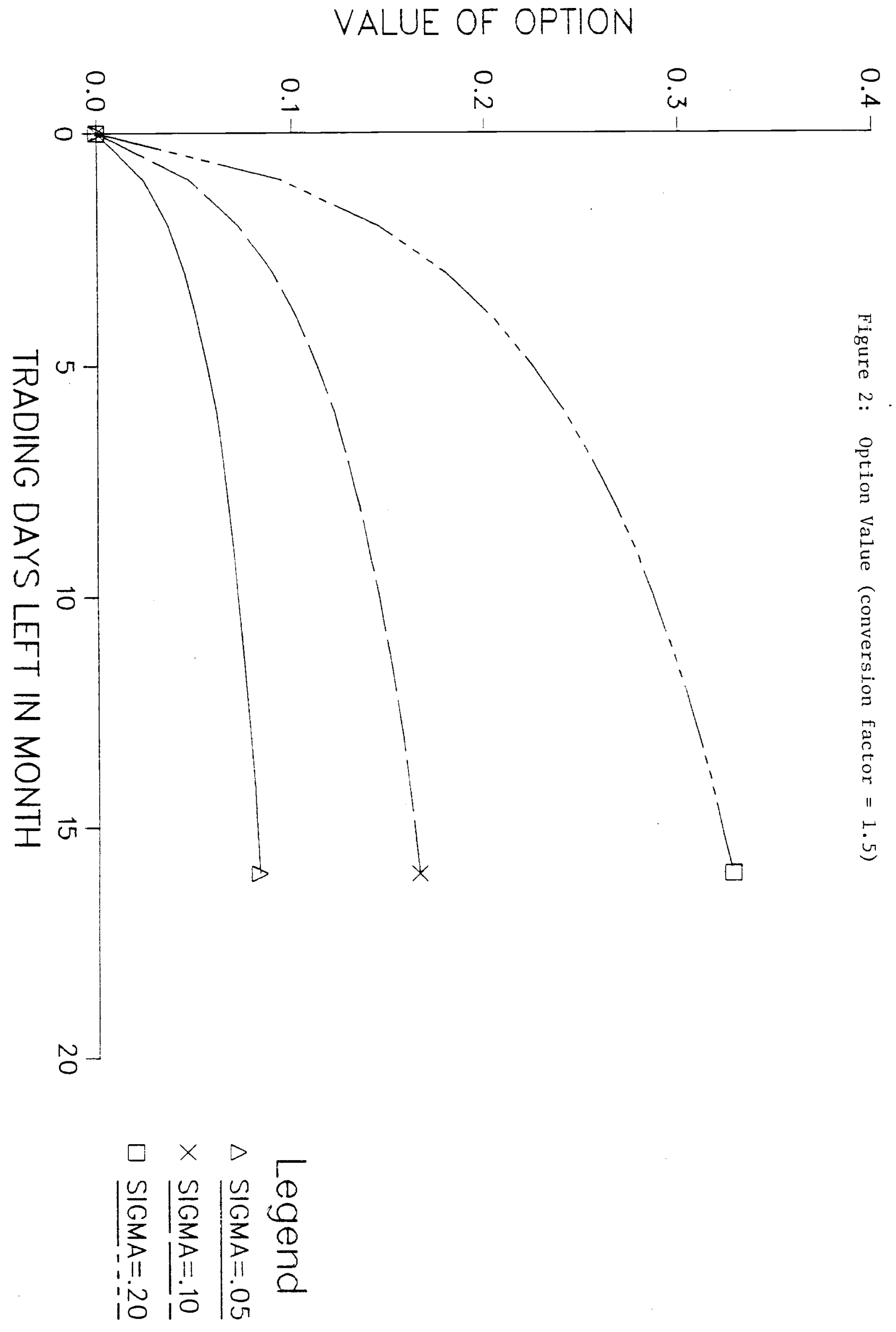


DECREASE IN BOND VALUE TO SETTLE
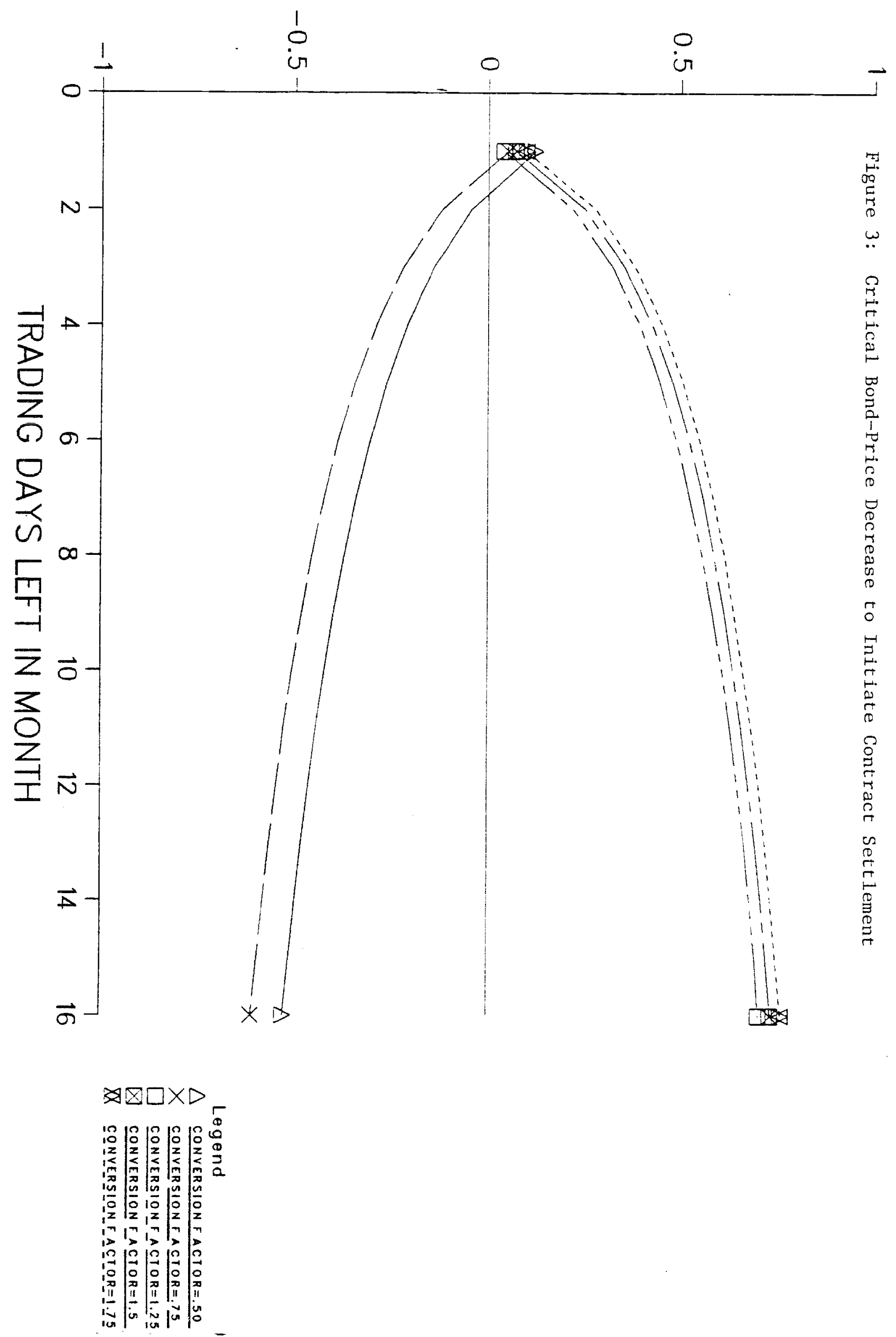
DECREASE IN BOND VALUE TO SETTLE

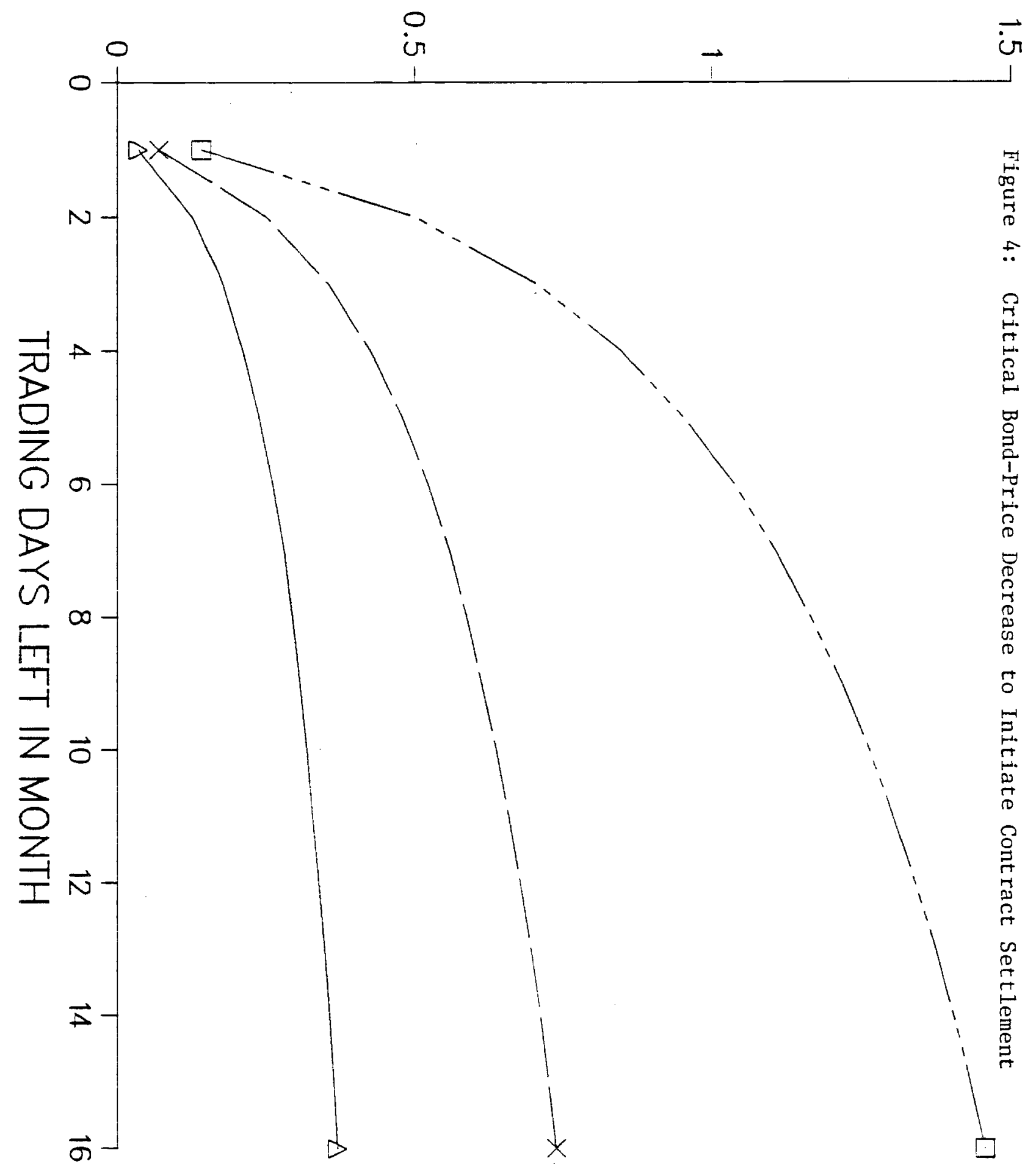

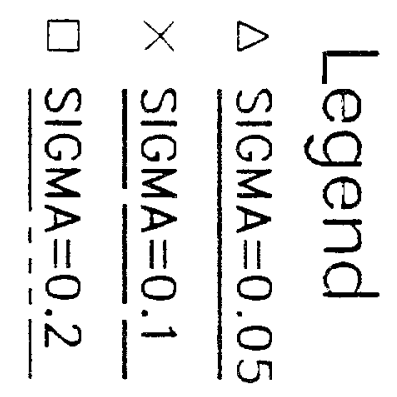




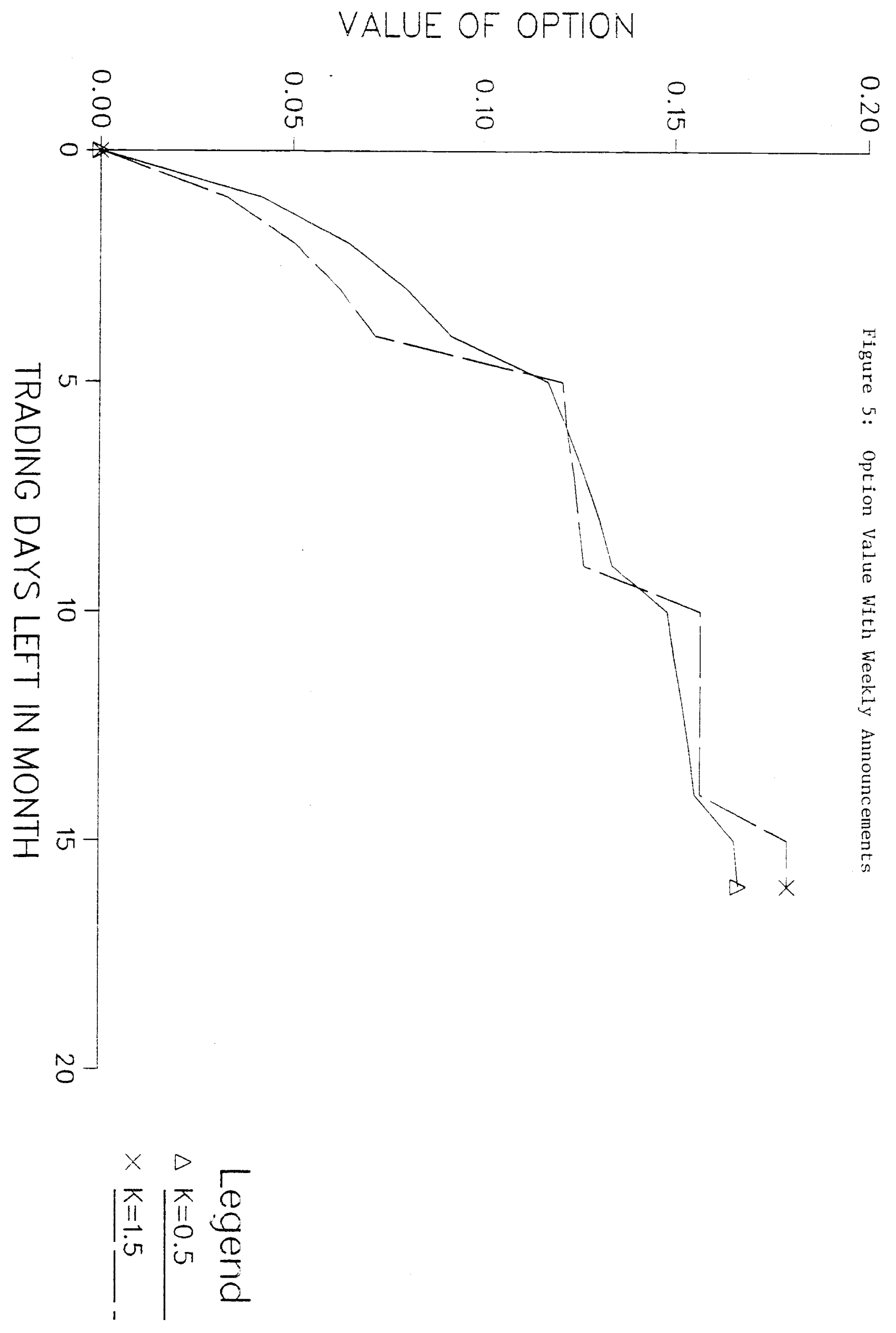


DECREASE IN BOND VALUE TO SETTLE

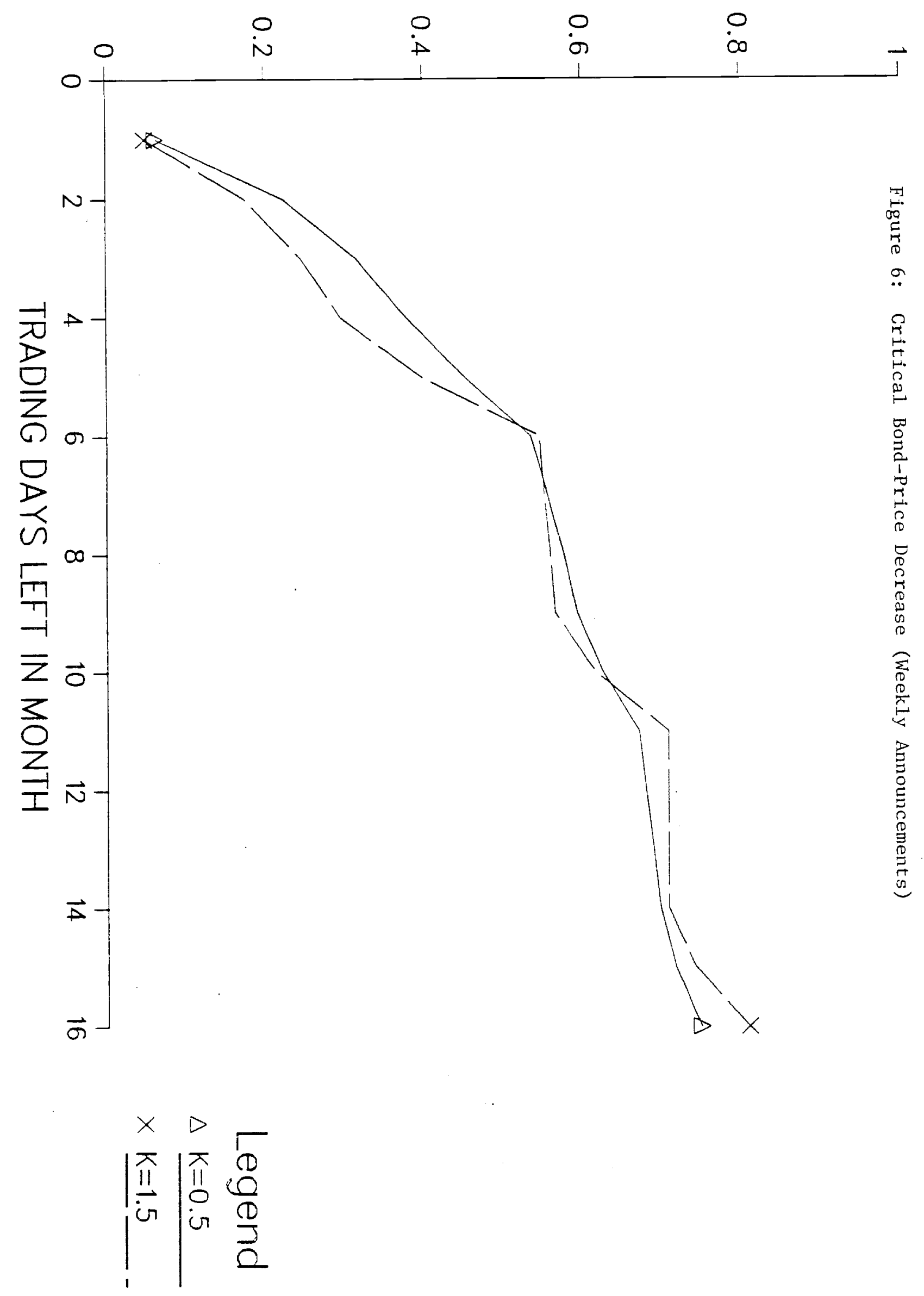

